\title{
Real-time emulation of parallel channel responses in the vertebrate retina and the primary visual cortex
}

\author{
Hirotsugu Okuno ${ }^{1 *}$, Tadashi Sanada', Jun Hasegawa², Tetsuya Yagi ${ }^{1}$ \\ From Twentieth Annual Computational Neuroscience Meeting: CNS*2011 \\ Stockholm, Sweden. 23-28 July 2011
}

In order to examine the functional roles of visual neurons in the retina and the cortex, responses of neurons to visual stimuli have been investigated physiologically, and discussions have been made using models derived from the physiological experiments. However, these discussions do not necessarily applicable to the case of highly complex visual environments wherein actual biological vision systems operate since they are based on the responses of a limited number of neurons to simple visual stimuli. In order to examine and discuss the functional roles of the neurons, a system that can emulate the responses of a group of model neurons in real time is required.

Thus far, a high-speed neural computation emulator with transient response has been developed mainly for engineering applications [1]. In this study, we have developed a system for the real-time reconstruction of neural activities with physiologically reasonable spatiotemporal properties using an analog-digital hybrid system comprised of analog resistive networks, fieldprogrammable gate arrays (FPGA), and a digital computer. The system reconstructs activities of $128 \times 128$

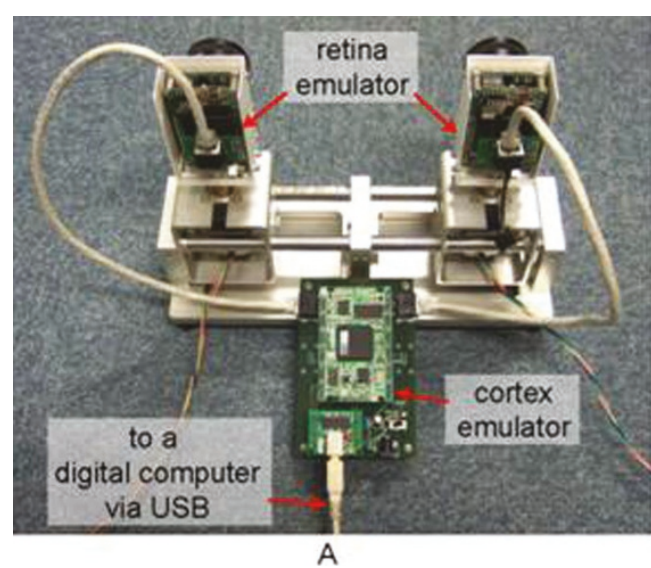

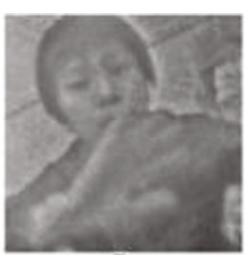

B

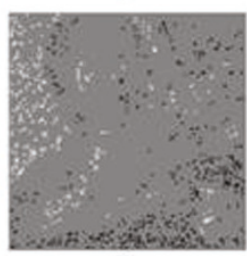

D

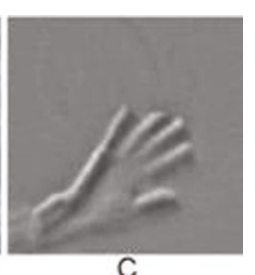

C

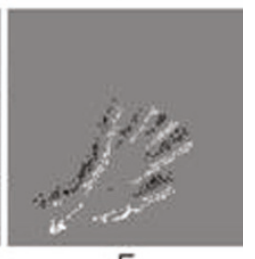

E

Figure 1 A. Appearance of the system comprised of two retina emulators, a cortex emulator, and a digital computer. B. Sustained response. C. Transient response. D. Sustained response with spike representation. E. Transient response with spike representation.

* Correspondence: h-okuno@eei.eng.osaka-u.ac.jp

'Graduate school of engineering, Osaka University, Osaka, 565-0871, Japan

Full list of author information is available at the end of the article

(C) 2011 Okuno et al; licensee BioMed Central Ltd. This is an open access article distributed under the terms of the Creative Commons 
neurons in each neural layer of the retina and the primary visual cortex at 200 frames per second.

The system consists of two retina emulators, a cortex emulator, and a digital computer (Fig.1(A)). The retina emulator emulates both the sustained and transient responses (Fig.1(B)1(C)), and their spike representations (Fig.1(D)1(E)). A part of detailed operation of the retina emulator is written in [2]. The cortex emulator receives spike signals from two retina emulators and emulates responses of cortex neurons including the simple and complex cells.

\section{Author details}

${ }^{1}$ Graduate school of engineering, Osaka University, Osaka, 565-0871, Japan.

${ }^{2}$ Commuture Information Systems Co., Ltd., Osaka, 564-0052, Japan.

Published: 18 July 2011

\section{References}

1. Serrano-Gotarredona R, Oster M, Lichtsteiner P, Linares-Barranco A, PazVicente R, Gomez-Rodriguez F, Camunas-Mesa L, Berner R, Rivas M, Delbruck T, et al: CAVIAR: a 45k neuron, 5M synapse, $12 \mathrm{G}$ connects/s AER hardware sensory-processing-learning-actuating system for high-speed visual object recognition and tracking. IEEE Trans Neural Netw 2009, 20:1417-1438.

2. Hasegawa J, Yagi T: Real-time emulation of neural images in the outer retinal circuit. J Physiol Sci 2008, 58:507-514.

doi:10.1186/1471-2202-12-S1-P378

Cite this article as: Okuno et al:: Real-time emulation of parallel channel responses in the vertebrate retina and the primary visual cortex. $B M C$

Neuroscience 2011 12(Suppl 1):P378.

\section{Submit your next manuscript to BioMed Central} and take full advantage of:

- Convenient online submission

- Thorough peer review

- No space constraints or color figure charges

- Immediate publication on acceptance

- Inclusion in PubMed, CAS, Scopus and Google Scholar

- Research which is freely available for redistribution

Submit your manuscript at www.biomedcentral.com/submit 